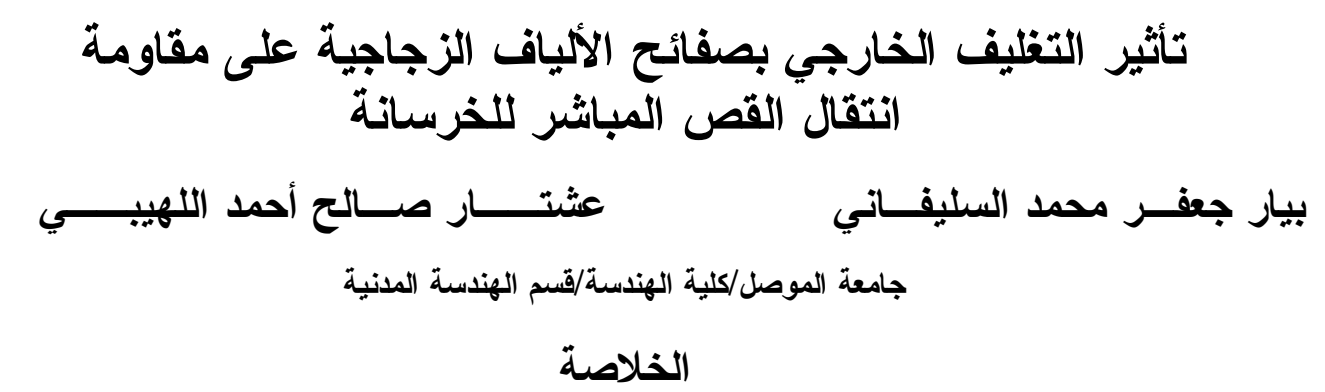

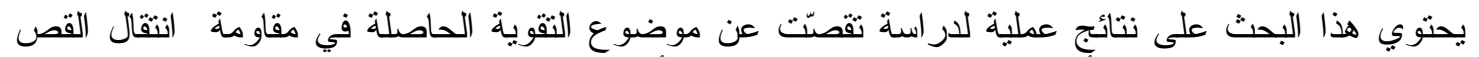

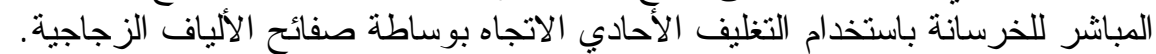
"اجريت هذه الدر اسة من خلال صب ثمان نماذج من نماذج نوع الدفع(Push-off Specimens) قسمت هذه الاهي

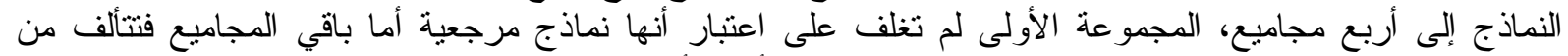

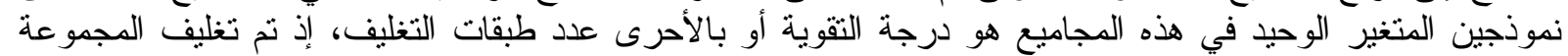

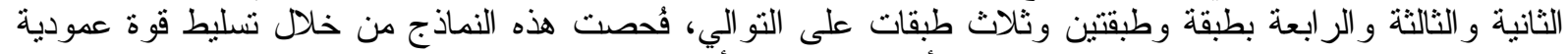

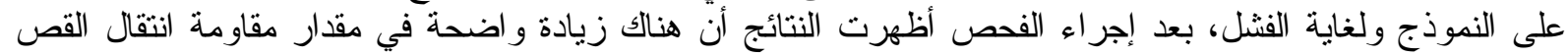

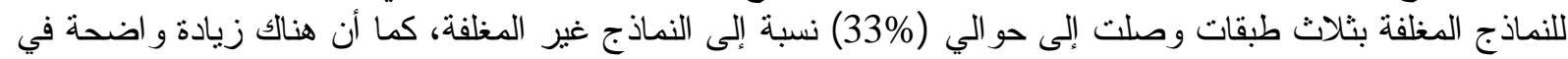

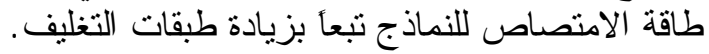

\title{
Effect Of Externally Bonded Gfrp Sheets On The Shear Transfer Capacity Of Concrete
}

\author{
Bayar J. Al-Sulayfani \\ Professor \\ Ashtar S. Al-Luhybi \\ Assistant Lecturer \\ University of Mosul/College of Engineering/Civil Engg. Dept.
}

\begin{abstract}
The current research includes practical results of study and investigated the subject of strengthening the shear strength through uniaxial confinement (one direction) using GFRP Sheets. This study was carried out by casting eight specimens (the push-off specimens group) which was divided in to four groups, the first non confined, being the reference group, the remaining groups consisted of two specimens each with only one variable being the degree of strengthening that is the numbers of confinement layers. The second, third, and fourth group were confined with one, tow, and three layers respectively. All specimens were tested through the application of a vertical load up to failure. The result indicated that there is a clear indication of shear strength increase amounting to $33 \%$ relative to the reference specimens (non confined), also there was a noticeable increase in the absorption capacity as a function of the number of confinement layers.
\end{abstract}

Key words: Strengthening, Shear Transfer on concrete, GFRP Sheets, Push-off specimens. 
إن اكتشاف مو اد البوليمر ومادة الاييوكسي بالتحديد كمادة رابطة ساهم بشكل كبير في استحداث تقنية جديــدة

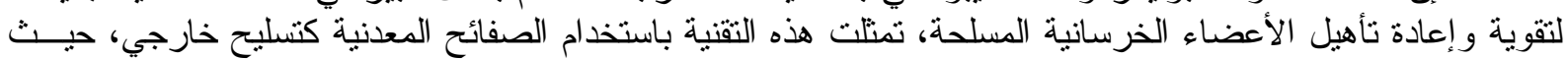

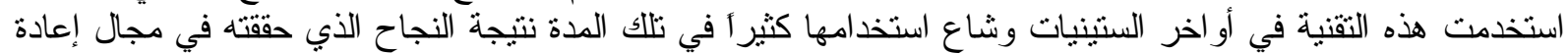

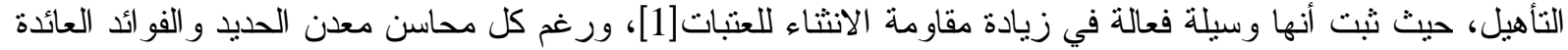

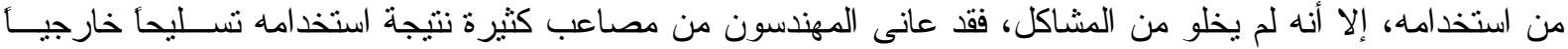

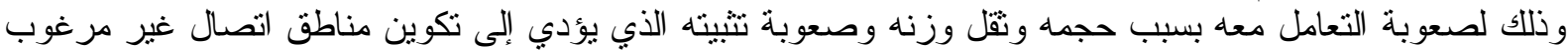

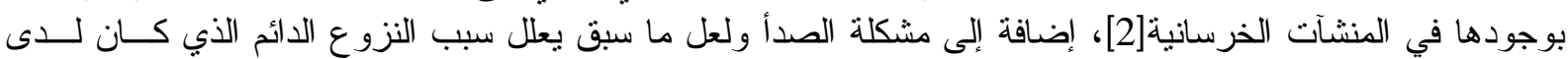

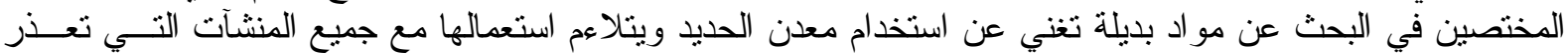

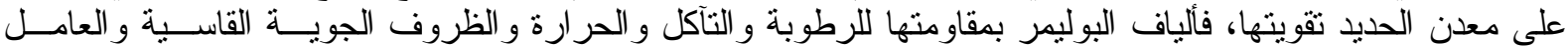

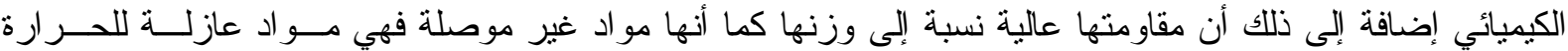
و الكهرباء، وكثافتها و اطئة و لا تحتاج إلى صيانة مستمرة ومن الممكن ربطها على الأعضاء الخرسانية] [3].

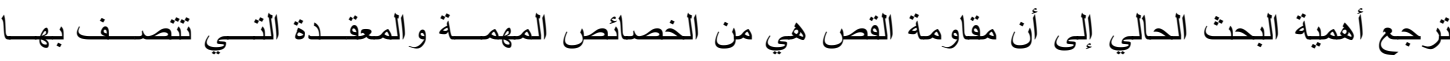

أهمية البحث

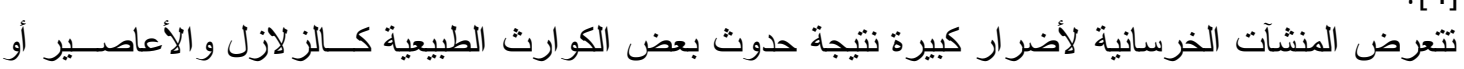

الخرسانت] [4].

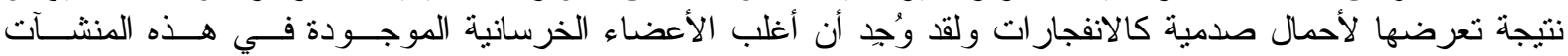

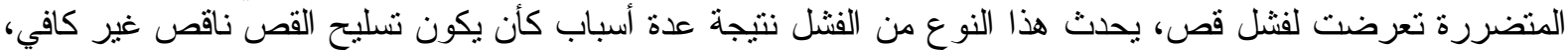

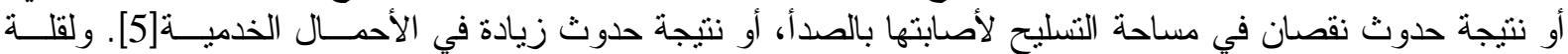

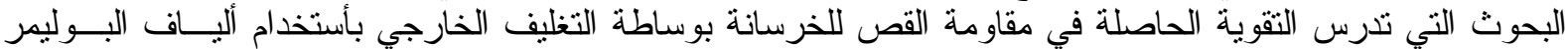

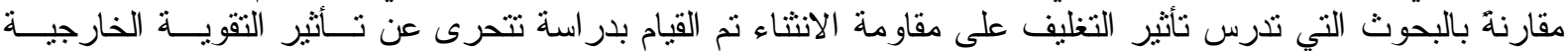

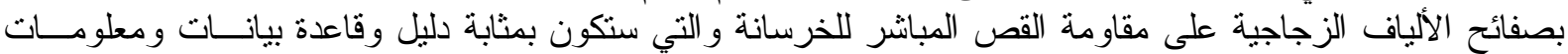

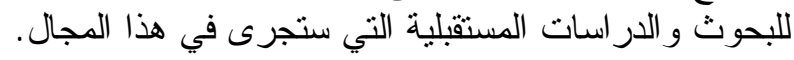

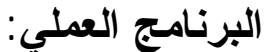 \\ نموذج الفحص}

تم أستخدام نموذج فحص الدفع (Push-off Specimen) كنموذج تجرى عليه الدر اسة الحالية، عرض وطول النمالي

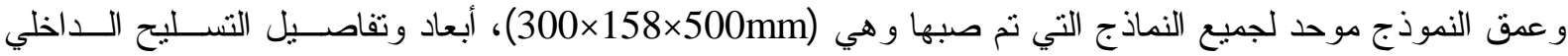

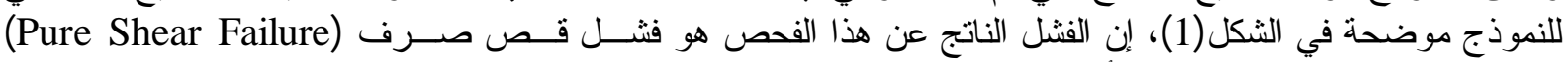

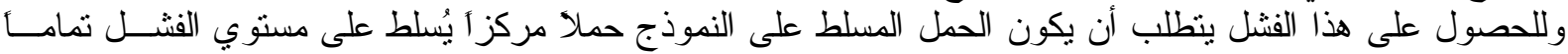

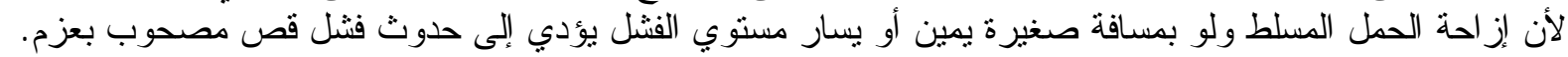

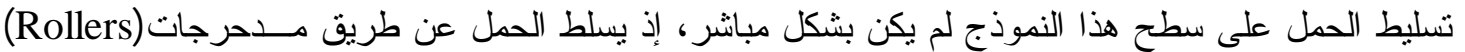

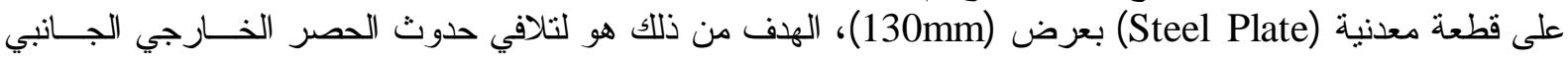
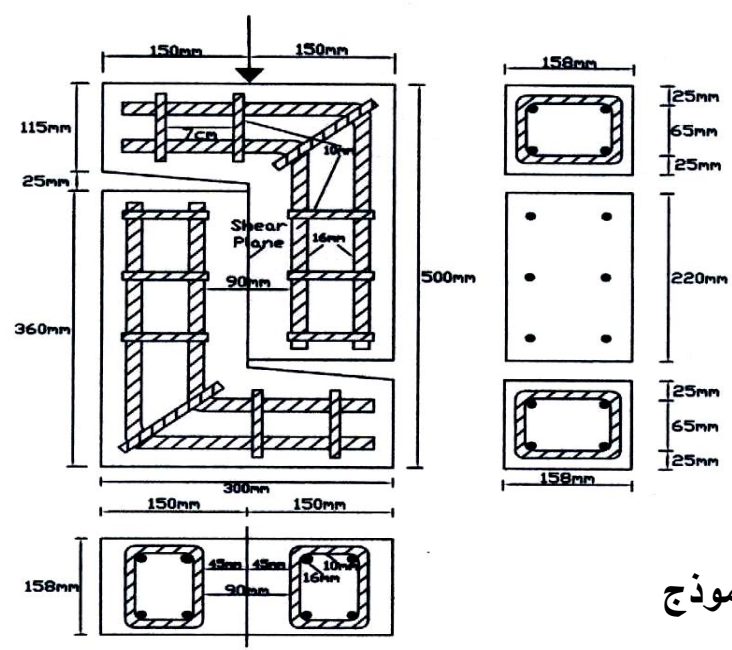

الثكل(1): أبعاد وتفاصيل التسليح الاخلي للنموذج 


\section{خواص المواد المستخدمة في الارسة}

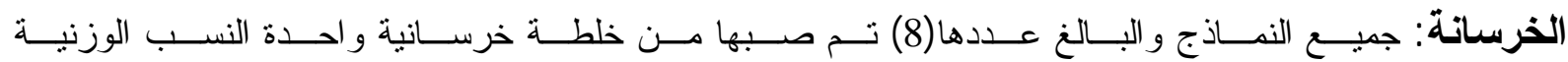

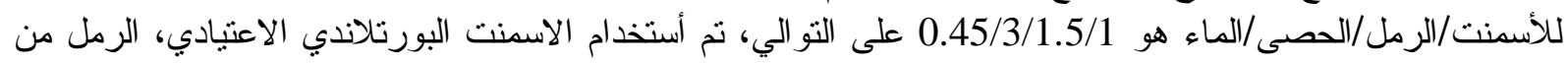

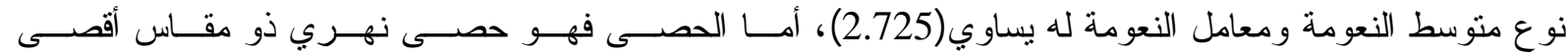
يساوي(20mm)، مقاومة الانضغاط للأسطو انة الخرسانية كانت بمقدار (36MPa).

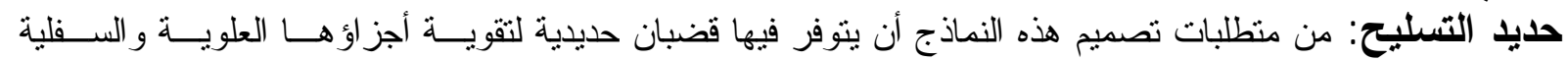

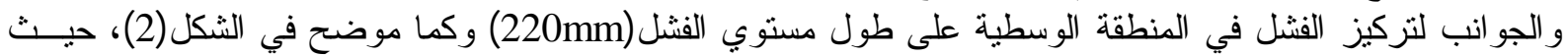

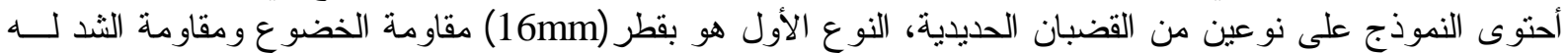

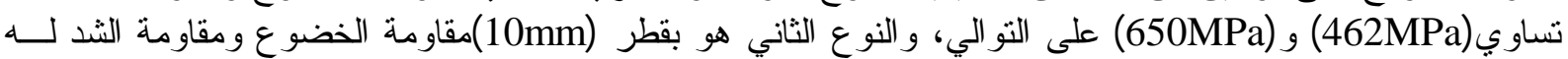
تساوي (627MPa) و (652MPa) على التو التي.

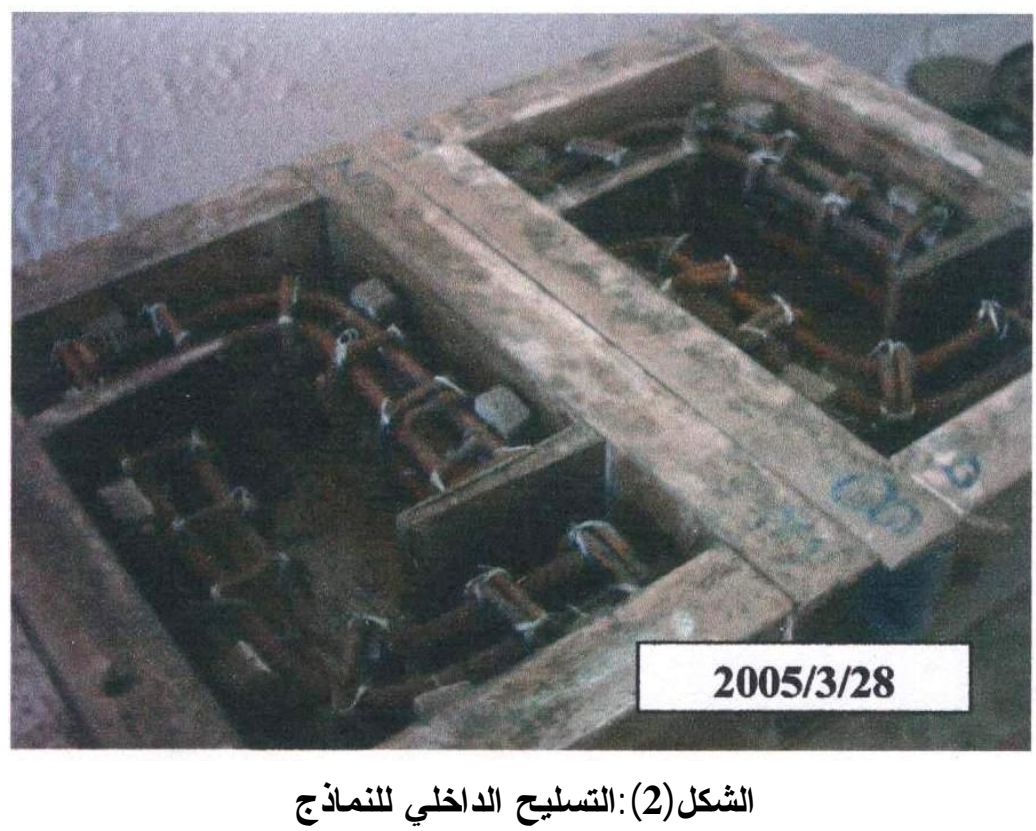

المـادة الر ابطة: إن عملية تغليف الأعضاء الخرسانية بصفائح الألياف الزجاجية لا يتم إلا بوجود مادة رابطة، تعهـل

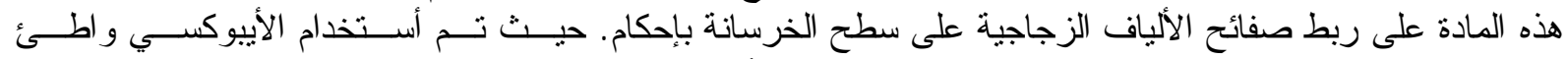

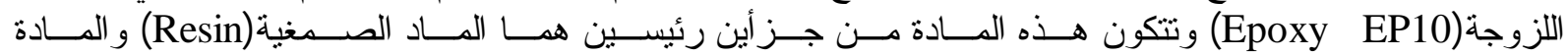

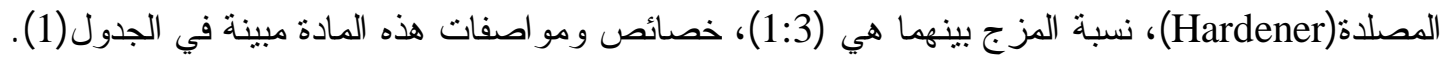

\section{(الجدول(1): خو اص الأيبوكسي نوع (Epoxy EP10)}

\begin{tabular}{||l||c||}
\hline \multicolumn{1}{|c|}{ Propertise } & Result of Testing \\
\hline \hline Pot. Life & $90 \mathrm{~min} . \mathbf{2 0}^{\circ} \mathrm{C}$ \\
$40 \mathrm{~min}$. & @ 35 $\mathrm{C}$ \\
\hline Density & $1060 \mathrm{Kg} / \mathrm{m}^{3}$ \\
\hline Tensile Strength & $29 \mathrm{~N} / \mathrm{mm}^{2} @ 7$ days \\
\hline Flexural Strength & $91 \mathrm{~N} / \mathrm{mm}^{2} @ 7$ days \\
\hline Compressive Strength & $57 \mathrm{~N} / \mathrm{mm}^{2} @ 1$ days \\
& $66 \mathrm{~N} / \mathrm{mm}^{2} @ 3$ days \\
\hline
\end{tabular}




\begin{tabular}{lllll} 
Al-Rafidain Engineering & Vol.17 & No.4 & August 2009 \\
\hline
\end{tabular}

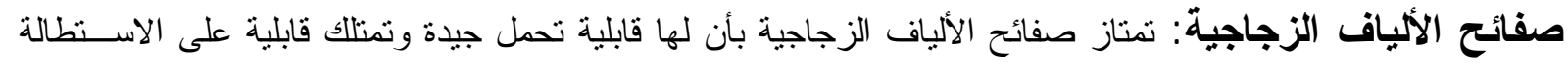

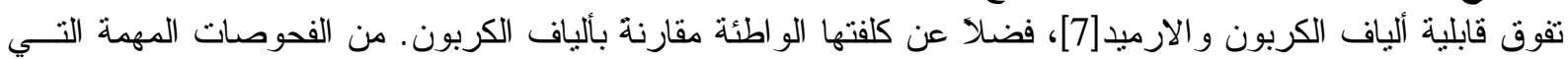

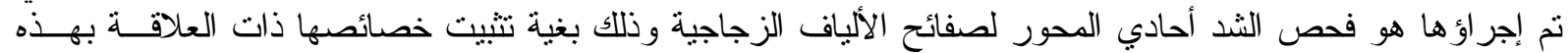

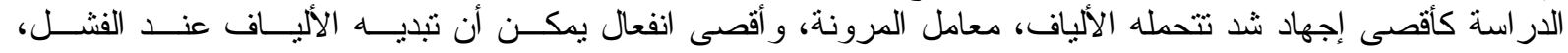
الجدول(2) يوضح مو اصفات الألياف الزجاجية.

\begin{tabular}{|c|c|c|c|}
\hline Properties & $\begin{array}{c}\text { Tensile Strength } \\
\text { (MPa) }\end{array}$ & $\begin{array}{c}\text { Modulus of } \\
\text { Elasticity (MPa) }\end{array}$ & Thickness(mm) \\
\hline $\begin{array}{l}\text { GFRP Sheet } \\
\text { coated with } \\
\text { Epoxy (Epoxy } \\
\text { EP10) }\end{array}$ & 108 & $30 \times 10^{3}$ & 1.07 \\
\hline
\end{tabular}

\section{تغليف النمـــــــــ}

بعد تصلب الخرسانة تبدأ مرحلة التغليف، حيث تتكون هذه المرحلة من عدة خطو ات تتمثل:

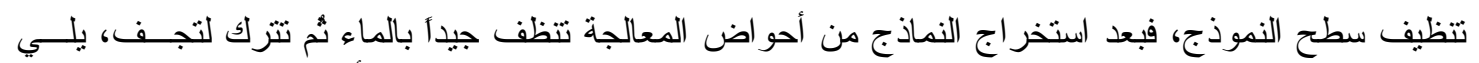

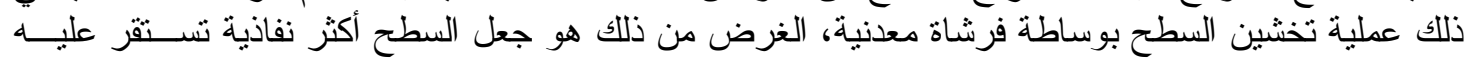

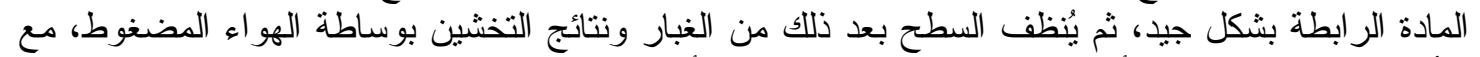

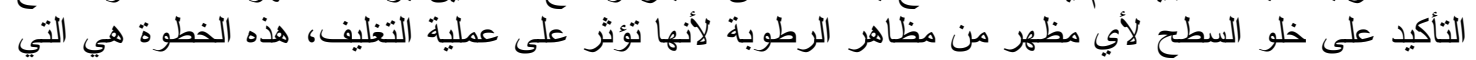

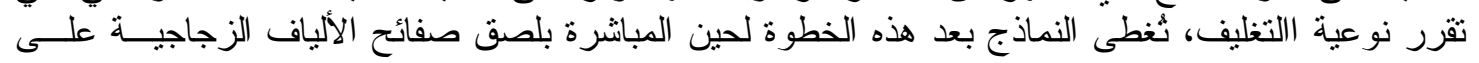
سطحها.

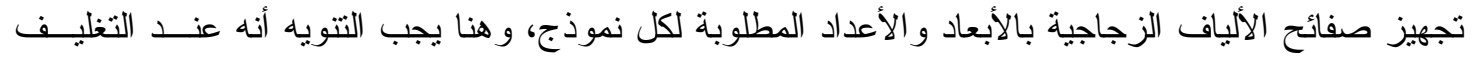

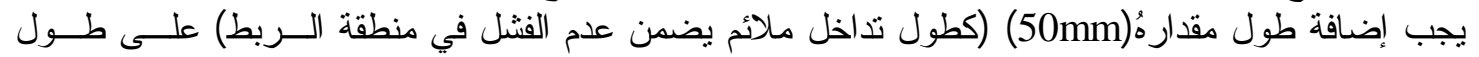

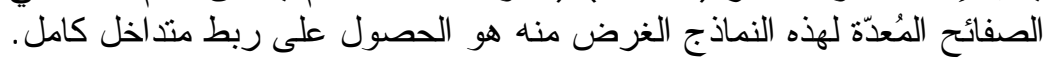

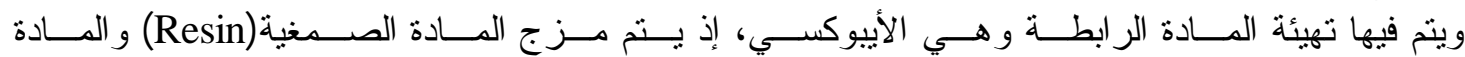

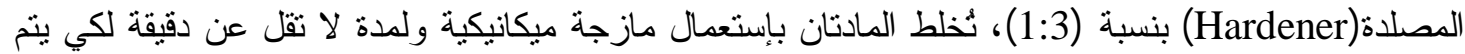

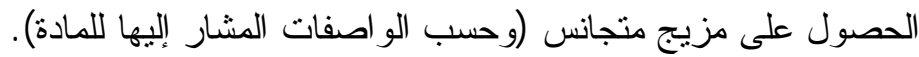

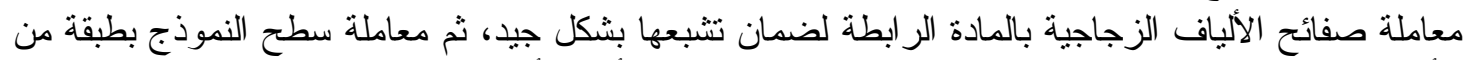

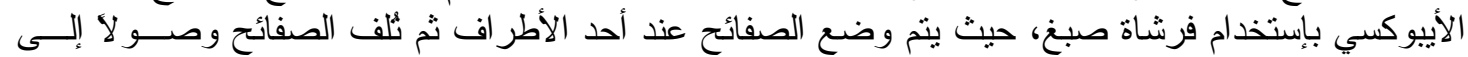

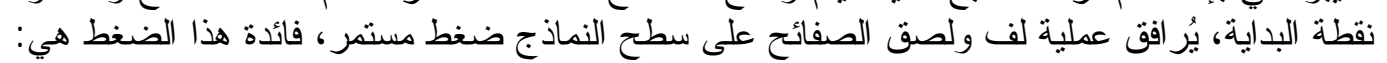

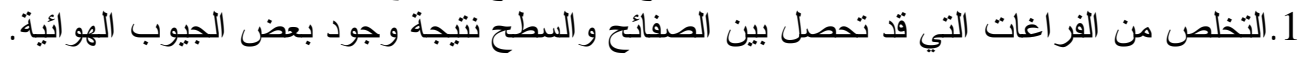

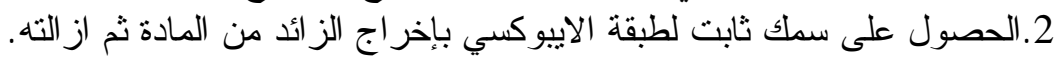

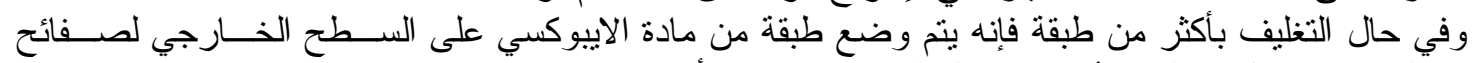

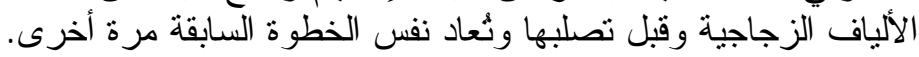

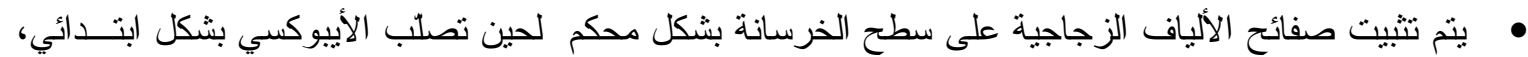

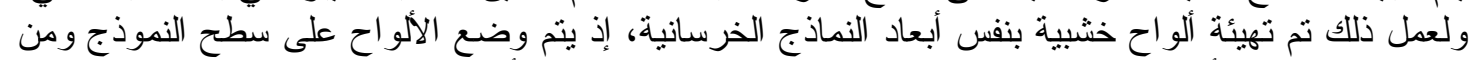

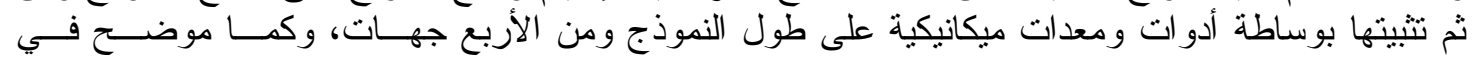

الثكل(3). 


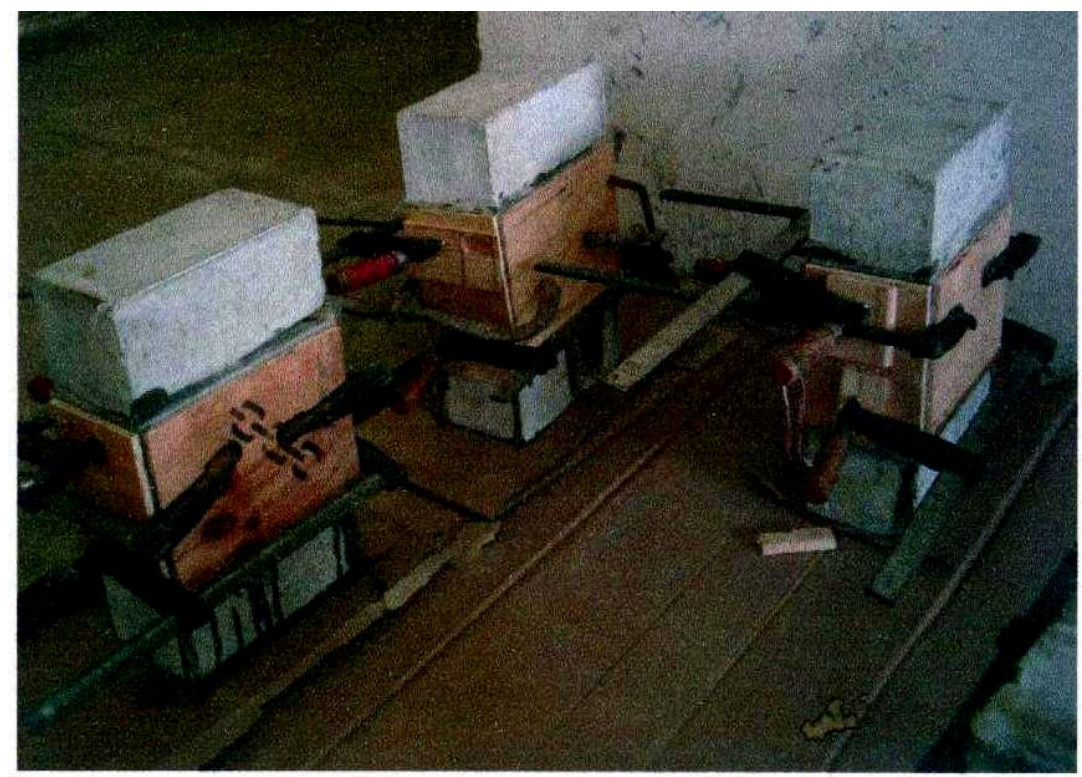

الثكل(3):نماذج فحص القص أثناء فترة التثبيت

\section{فحص النماذج}

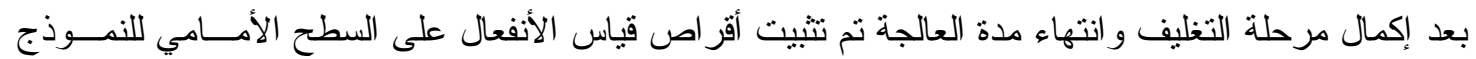

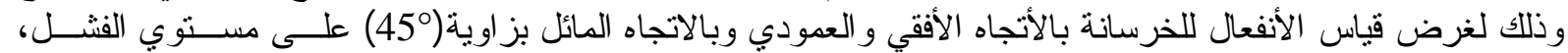

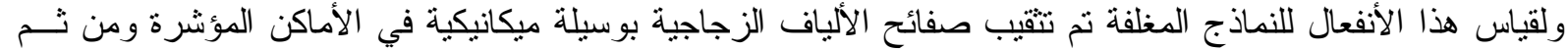

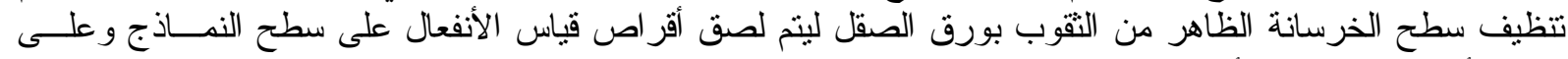
نفس الأبعاد المثبتة بها الأقر اص في النماذج غير المغلفة وكما موضح في الثكل(4).
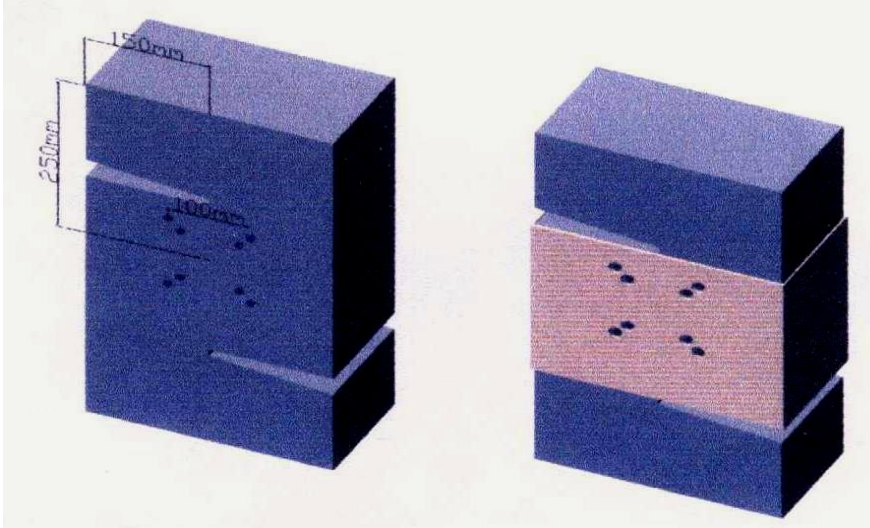

\section{الثكل(4):تثبيث أقر اص قياس الأفعال بالنسبة للنماذج المغلقة}

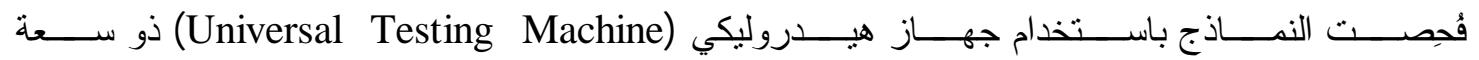

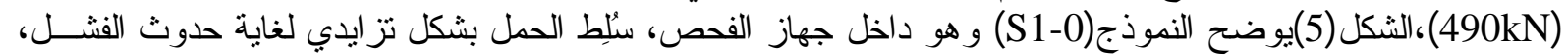

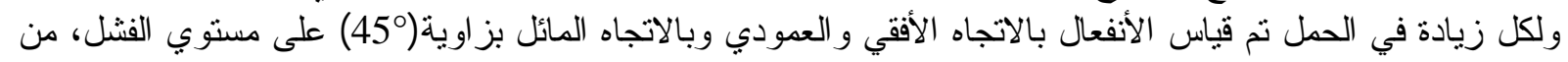

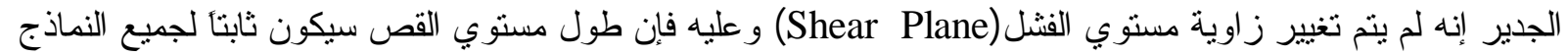
و الذي يساوي(220mm). 


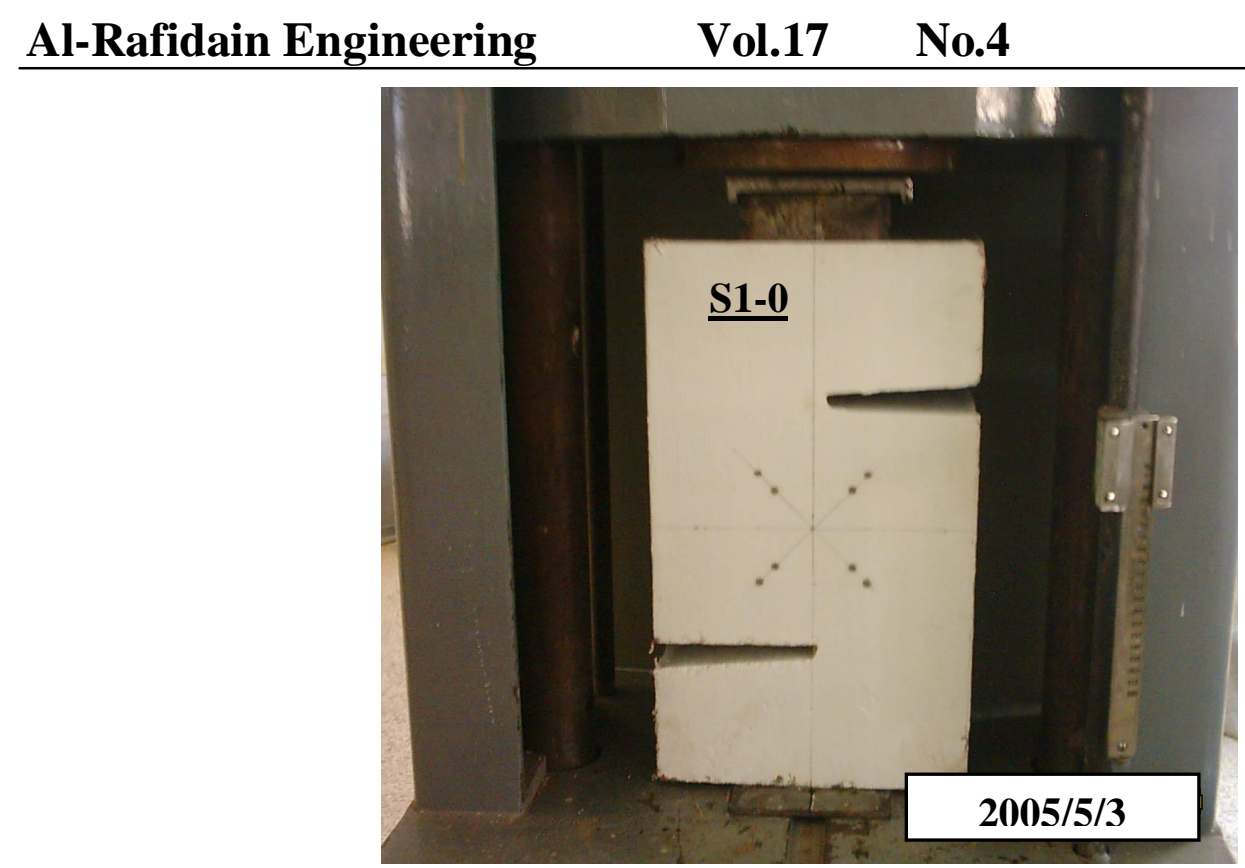

الشكل(5): نموذج فحص القص (S1-0) داخل جهاز الفحص

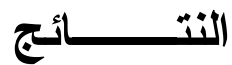

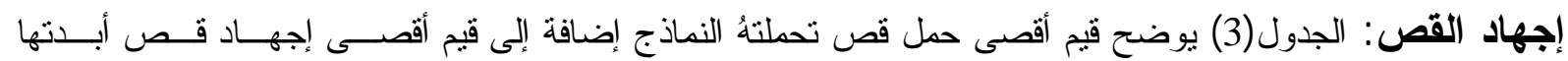
النماذج الني يُمكن الحصول عليها بقسمة قوة القص على مساحة مستوي الفنل و المساوية (158×20mm). الجدول(3): نتائج نماذج فحص القص

\begin{tabular}{|c|c|c|c|c|c|c|}
\hline Specimen & $\begin{array}{l}\text { No. of } \\
\text { layout }\end{array}$ & $\begin{array}{l}\text { Average } \\
\text { Comp. } \\
\text { Strength } \\
(\mathrm{MPa})\end{array}$ & $\begin{array}{c}\text { Shear } \\
\text { force Vu } \\
(\mathbf{k N})\end{array}$ & $\begin{array}{c}\text { Average } \\
\text { Shear } \\
\text { force Vu } \\
(\mathbf{k N})\end{array}$ & $\begin{array}{c}\text { Shear Stress } \\
\text { (MPa) } \\
\boldsymbol{\tau}\end{array}$ & $\begin{array}{c}\text { Average } \\
\text { Shear Stress } \\
\text { (MPa) } \\
\tau\end{array}$ \\
\hline S1-0 & \multirow{2}{*}{$\mathbf{0}$} & \multirow{2}{*}{35.5} & 177.5 & \multirow{2}{*}{186} & 5.1 & \multirow{2}{*}{5.4} \\
\hline S2-0 & & & 195.2 & & 5.6 & \\
\hline S3-1 & \multirow{2}{*}{1} & \multirow{2}{*}{36.2} & 213.8 & \multirow{2}{*}{208} & 6.2 & \multirow{2}{*}{6} \\
\hline S4-1 & & & 202 & & 5.8 & \\
\hline S5-2 & \multirow{2}{*}{2} & \multirow{2}{*}{36.8} & 225.6 & \multirow{2}{*}{223.6} & 6.5 & \multirow{2}{*}{6.45} \\
\hline S6-2 & & & 221.6 & & 6.4 & \\
\hline S7-3 & \multirow{2}{*}{3} & \multirow{2}{*}{36.5} & 250.1 & \multirow{2}{*}{251.8} & 7.2 & \multirow{2}{*}{7.25} \\
\hline S8-3 & & & 253.5 & & 7.3 & \\
\hline
\end{tabular}

*قيم مقاومة الأضضغاط تم الحصول عليها بعد فحص أسطو انات قياسية بإبعاد (150X300mm) 


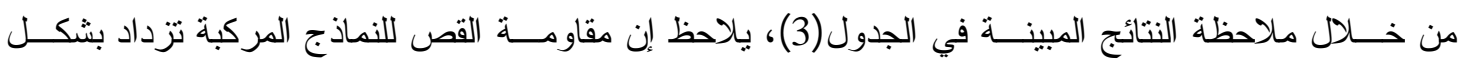

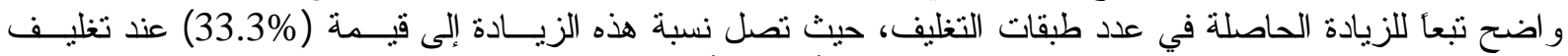

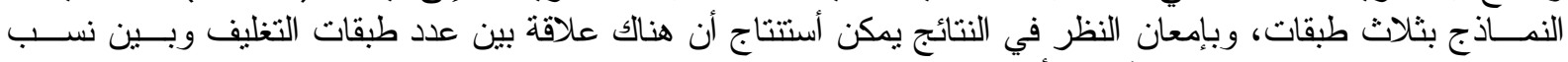

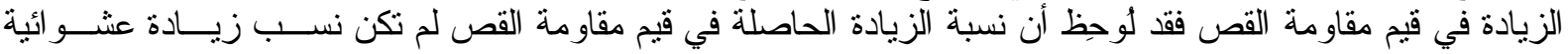

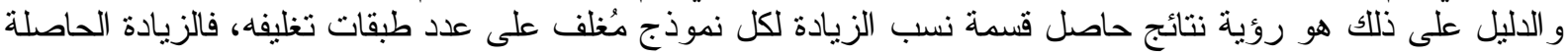

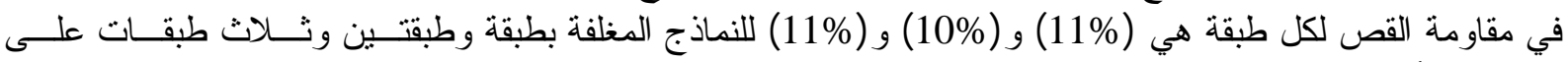

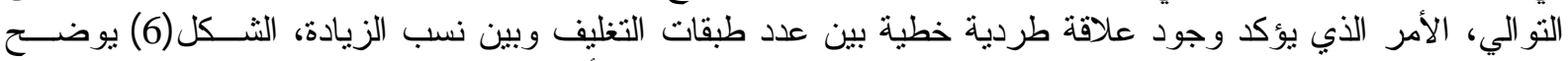

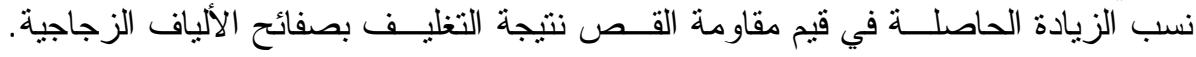

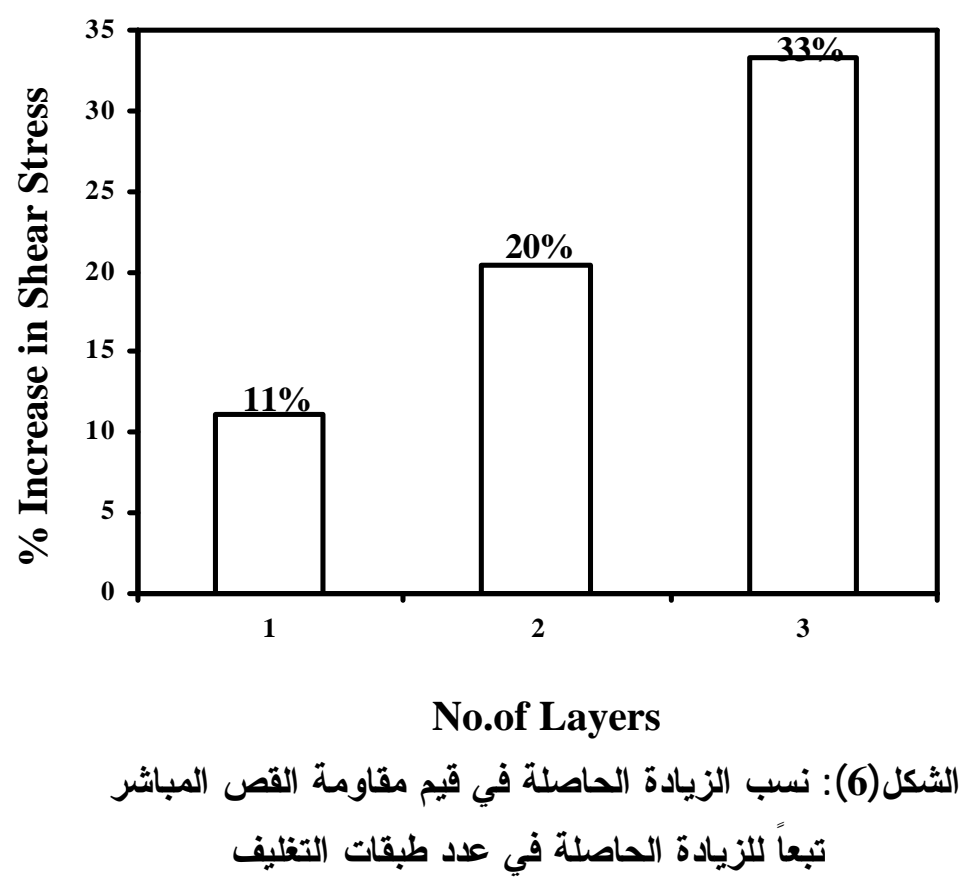

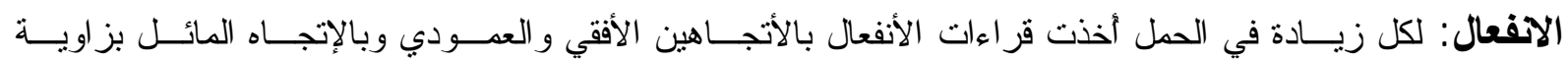

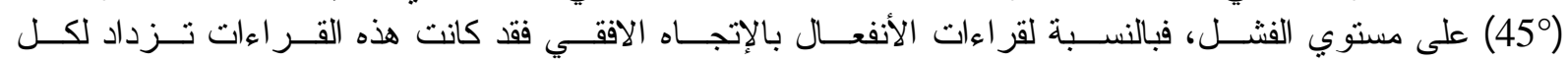

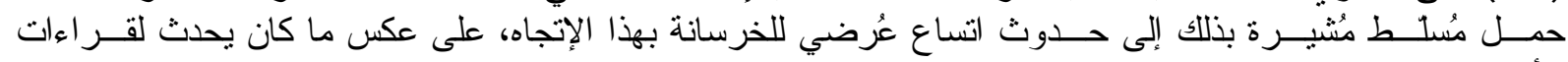

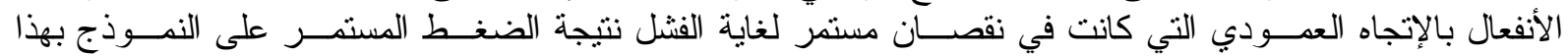

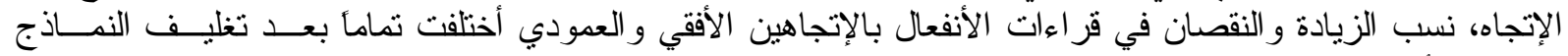

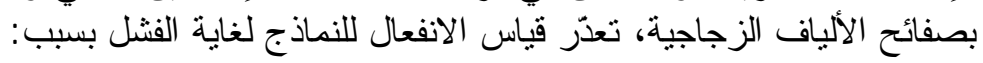

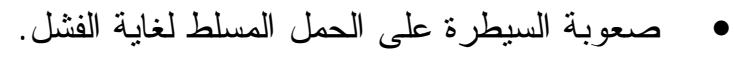
• • • • • • •

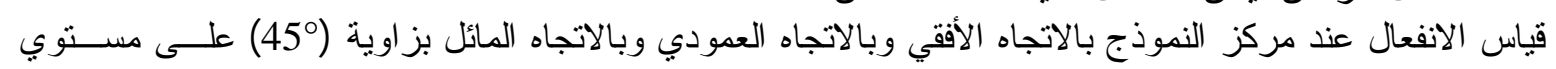

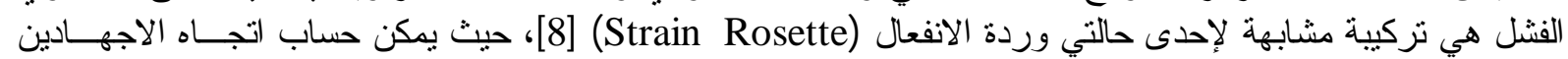

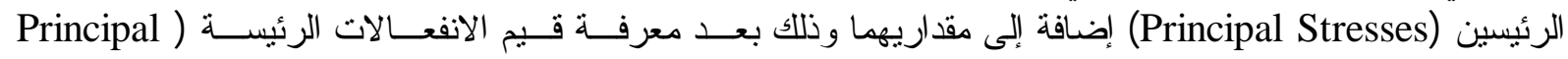

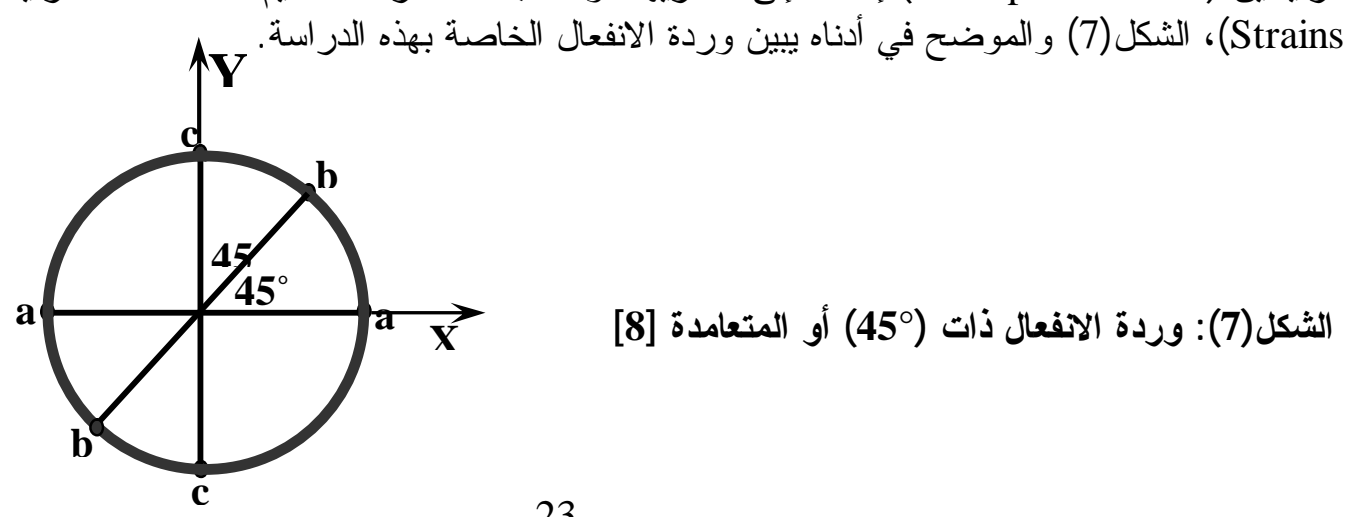


وباستخدام زو ايا الانفعالات الثتلاثة الخطية والاستفادة من المعادلات الخاصة بهذه الحالة يمكن إنشـــاء دائــرة

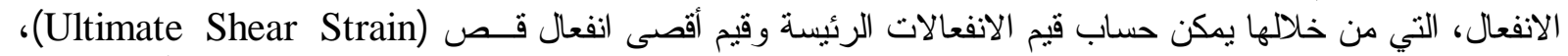

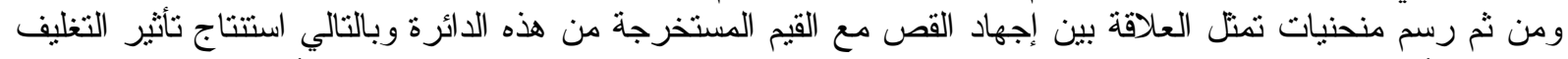

بصفائح الألياف الزجاجية على هذه النتائج، فالثكل(8) يوضح مندــني العلاقة ( إجهاد القص - الأنفعالات الرئيسة ).

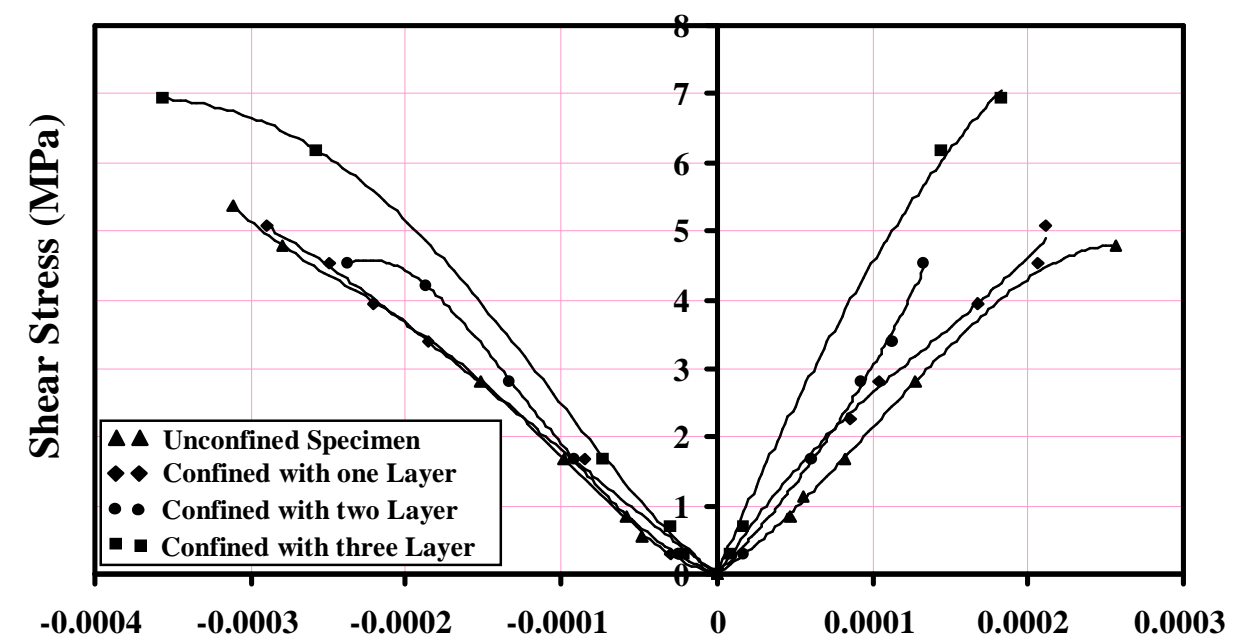

\section{Principal Strain $(\mathbf{m m} / \mathbf{m m})$}

الثنكل(8): منحني علاقة (إجهاد القص -الانفعالات الرئيسة) للنماذج غير المغلقة والنماذج المغلفة

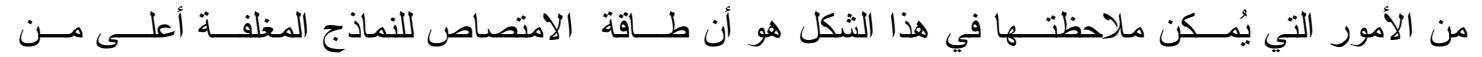

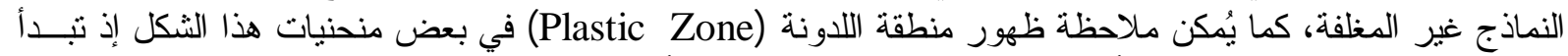

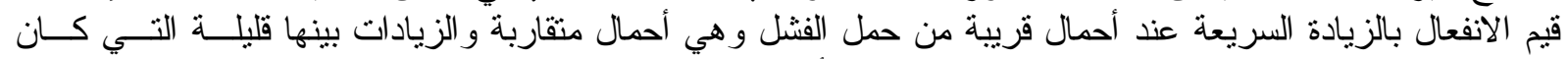

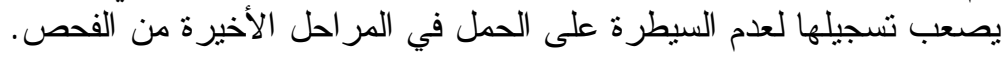

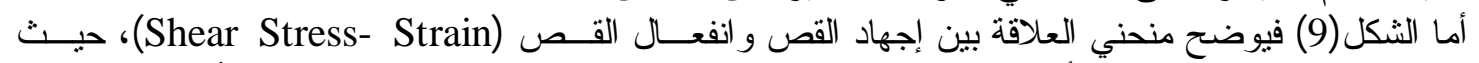

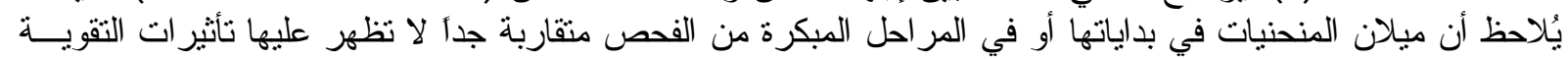

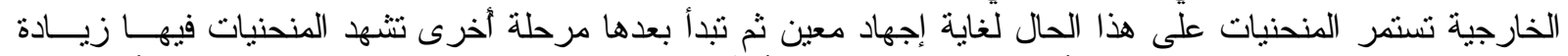

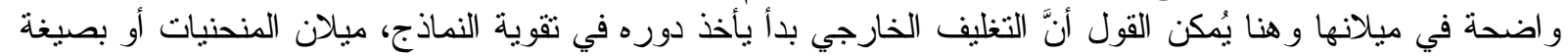

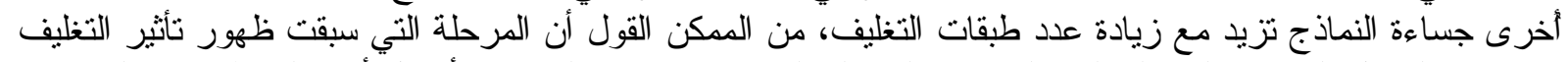

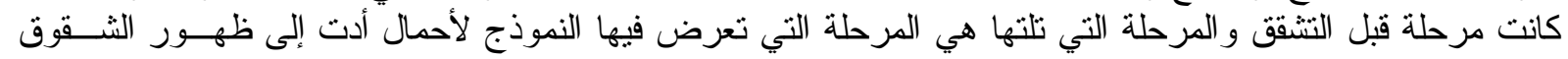

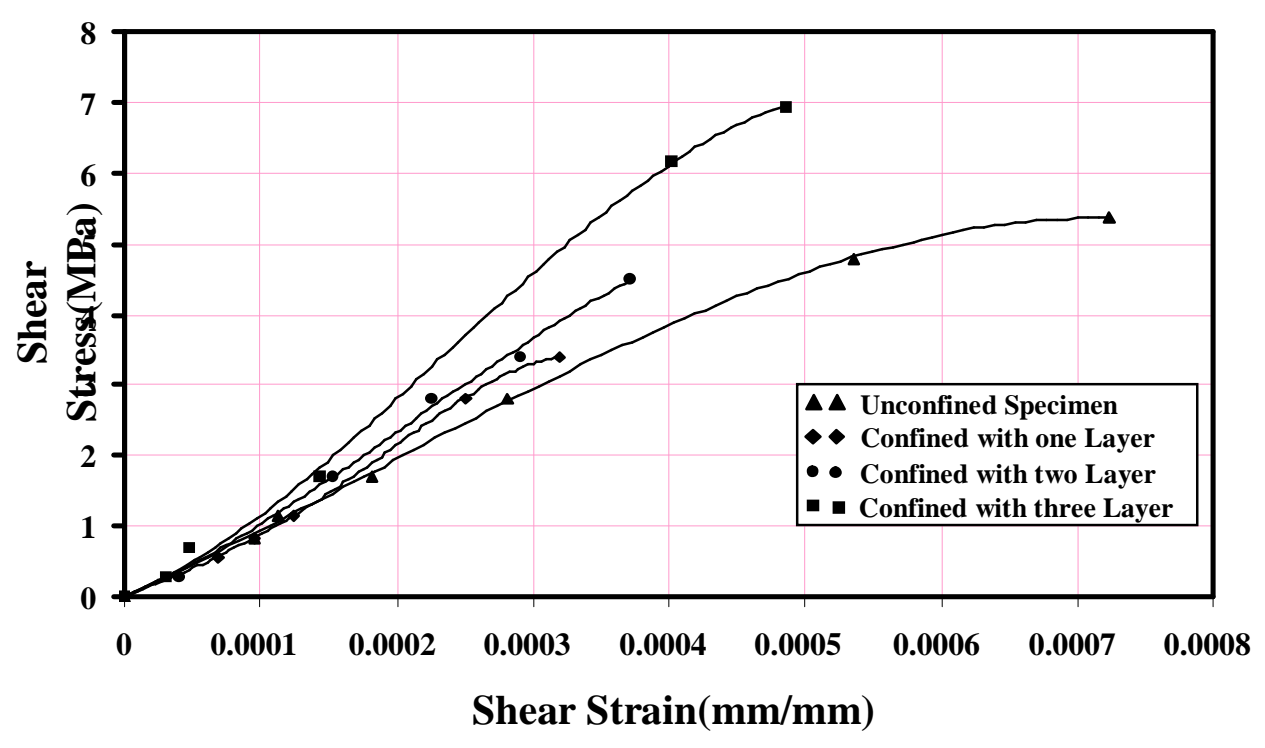

الثكل(9): منحني علاقة (إجهاد القص -انفعال القص) 


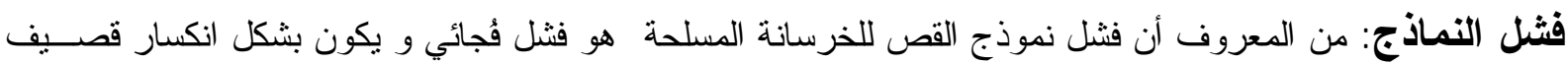
Further (Brittle Fracture)

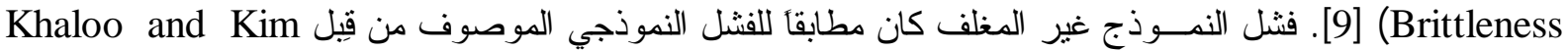

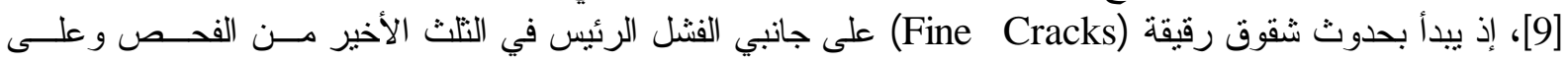

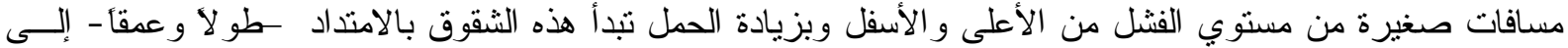

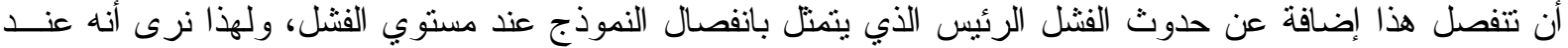

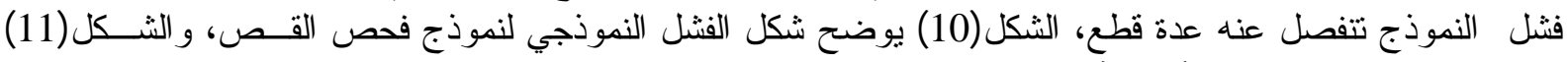
يوضح شكل الفنشل للنموذج (S1-0) غير المغلف الخاص بالدر اسة الحالية.

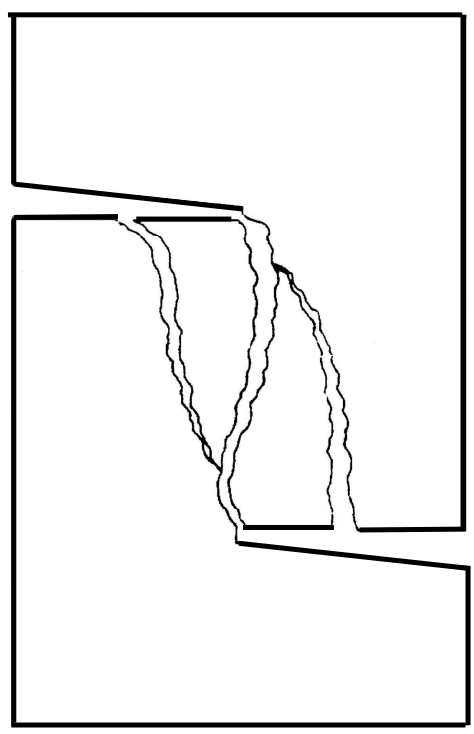

الشكل(10): شكل الفشل النموذجي لنماذج فحص القص [9]

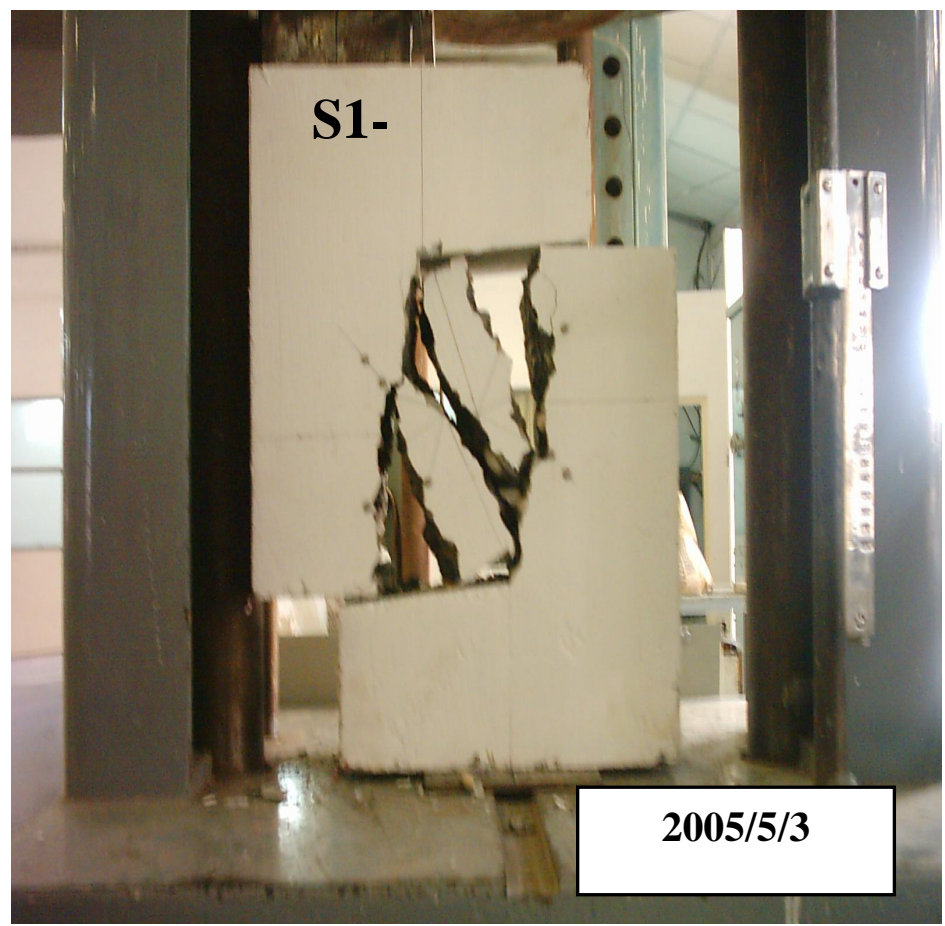

الثكل (11): نموذج فحص القص (S1-0) بعد الفشل 


\section{$\begin{array}{lllll}\text { Al-Rafidain Engineering } & \text { Vol.17 } & \text { No.4 } & \text { August } 2009\end{array}$}

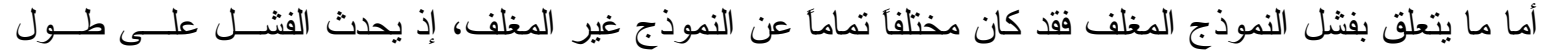

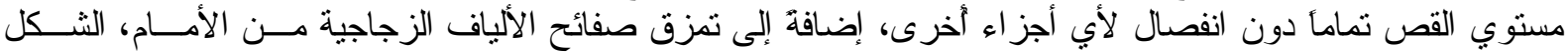

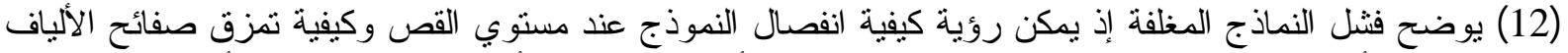

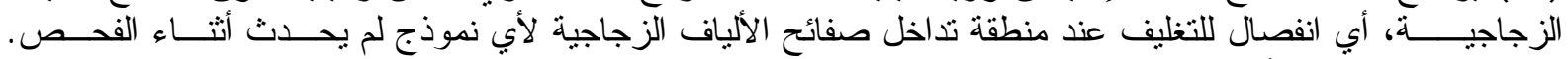

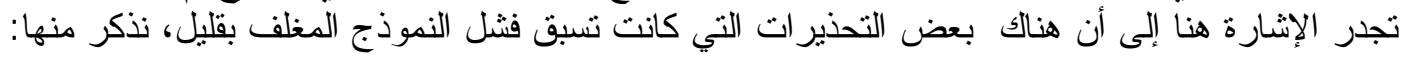

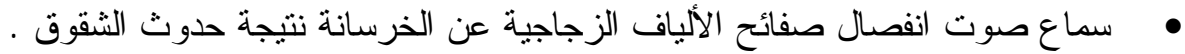

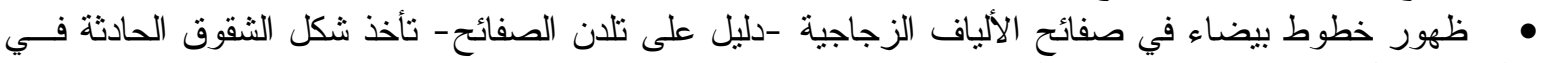

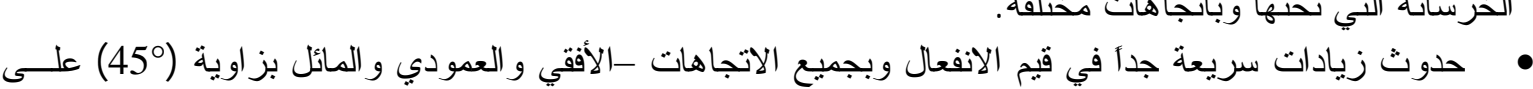
مستوي الفشل -.

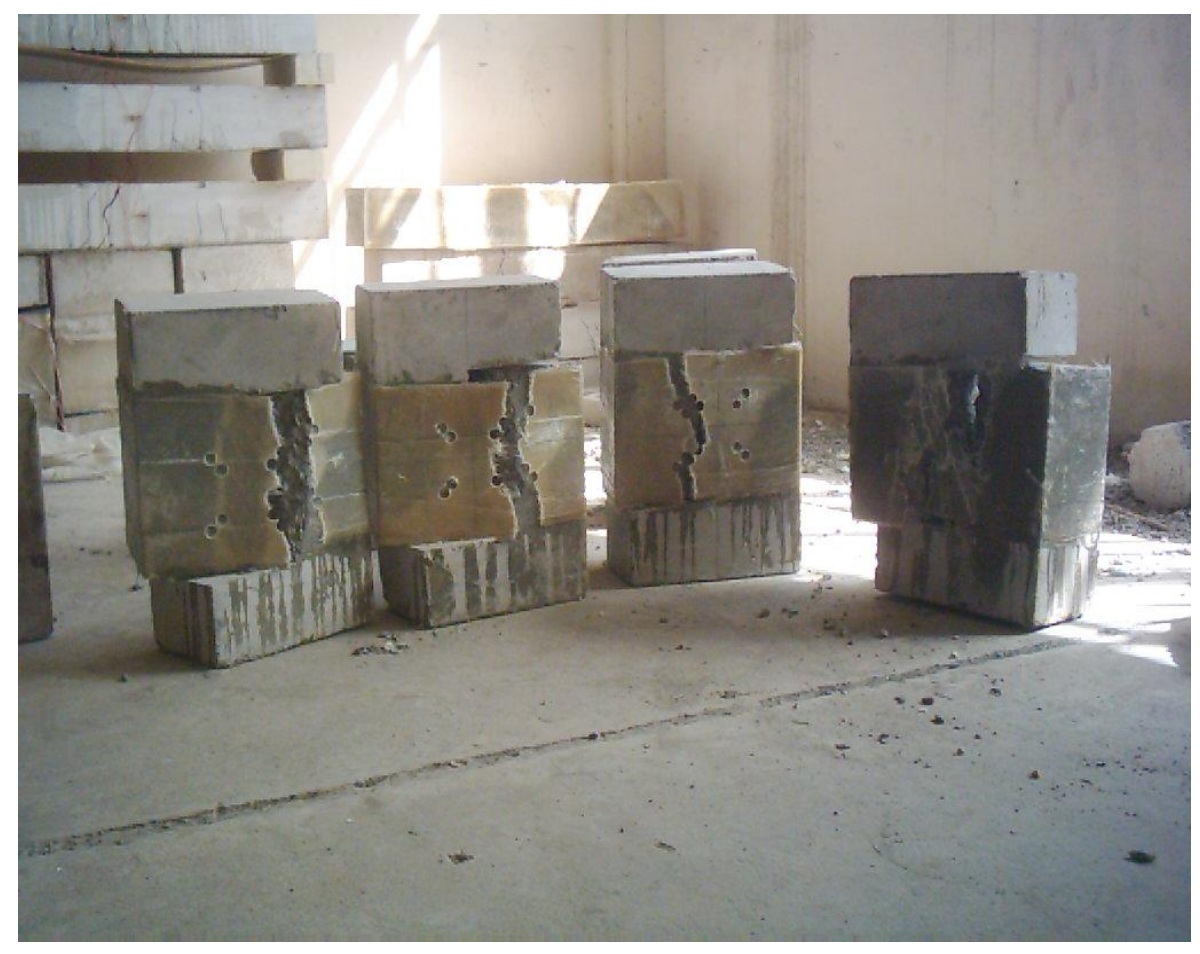

الثكل(12): شكل الفشل للنماذج المغلفة

\section{الاستنتتاجــــات}

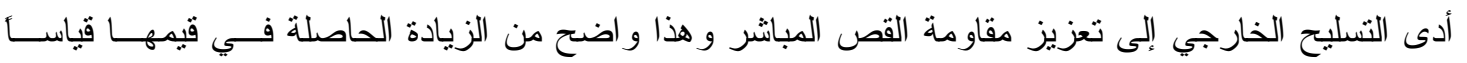

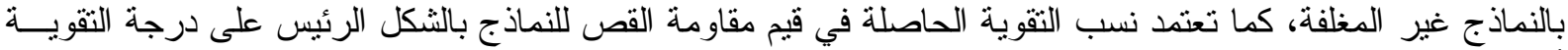

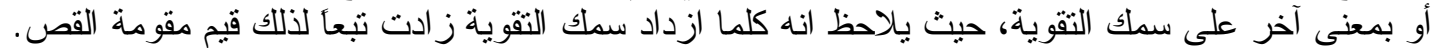

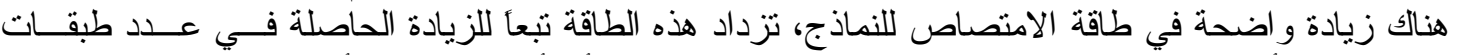

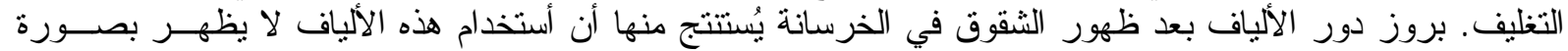

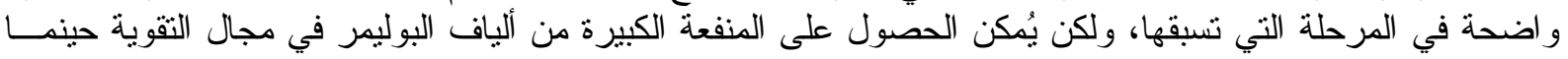

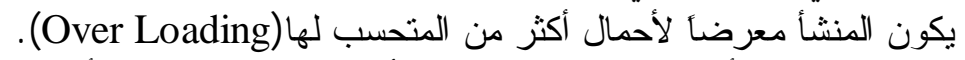

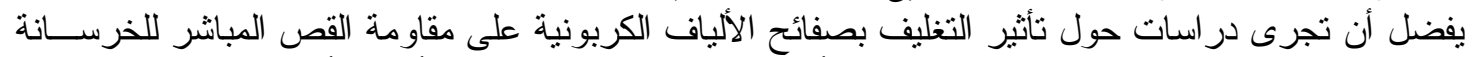

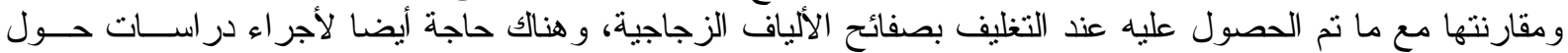
تأثير تغيير زو ايا التغليف بصفائح ألياف البوليمر على مقاومة القص المبانشر للخرسانة. 


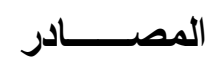

1. Lamanna, A.J., "Flexural Strengthening of Reinforced Concrete Beams with Mechanically Fastened Fiber Reinforced Polymer Strips", Ph.D. Thesis, University of Wisconsin-Madison, 2002, 287pp.

2. GangaRao, H.V. and Vijay, P.V., "Bending Behavior of Concrete Beams Wrapping with Carbon Fabric", Journal of Structural Engineering, Vol. 124, No. 1, January, 1998, pp. 3-10.

3. Moulsdale, M., "Behaviour of Externally Confined High Strength Concrete Columns under Eccentric Loading”,Broject Bachelor of Engineering, University of Wollongong Faculty of Engineering, November, 2002.

4. Alagusundaramoorthy, P., Harik, I.E. and Choo, C.C., "Shear Strength of R/C Beams Wrapped with CFRP Fabric", Research Report KTC-02-14/SPR 200-99$\mathbf{2 F}$, University of Kentucky,College of Engineering, August, 2002, pp. 1-24.

5. Khalifa, A. and Nanni, A., "Improving Shear Capacity of Existing R/C TSection Beams Using CFRP Composites", Cement and Concrete Composites, Vol. 22, No. 2, July, 2000, pp. 165-174.

6. Mattock, A.H., "Shear Transfer in Concrete Having Reinforcement at an Angle to the Shear Plane", ACI Special Pubilication SP-42, Vol. 1, 1974, pp.17-42.

7. Wabo Mbrace Company, "Composite Strengthening System", 3 th Edition, Watson Bowman Acme Corp., May, 2002, 103pp.

8. Pytel, A. and Singer, F.L., "Strength of Materials", $4^{\text {th }}$ Edition, Harper and Row, Publishers, New York, 1987, 594pp.

9. Khaloo, A.R. and Kim, N., "Influence of Concrete and Fiber Characteristics on Behavior of Steel Fiber Reinforced Concrete under Direct Shear", ACI Maretials Journal, Vol. 94, No. 6, November-December., 1997, pp. 592-601.

تم اجراء البحث في كلية الهنسسة - جامعة الموصل 